\title{
Consensus algorithm of the American Diabetes Association and the European Association for the Study of Diabetes: some concerns
}

\author{
A. Ceriello \\ Received: 13 November 2008 / Accepted: 23 January 2009 /Published online: 10 June 2009 \\ (C) Springer-Verlag 2009
}

\section{Abbreviation \\ ADA American Diabetes Association}

To the Editor: The recent algorithm connected with the American Diabetes Association (ADA) and the European Association for the Study of Diabetes, published simultaneously in Diabetologia [1] and Diabetes Care [2], in my opinion, raises several concerns that require some consideration. The first concern is that it is still defined as the 'ADA-EASD algorithm', as neither the ADA nor the EASD has ever, even in the past, endorsed it.

In the article it is clearly stated that it only represents the opinion of the authors. This means that the algorithm is just the opinion of several experts and should not be further defined as an 'ADA-EASD algorithm'.

Second, the authors also refer to the consensus as guidelines. This is difficult to understand, as the process for the development of guidelines is usually more comprehensively defined [3]. Third, the authors divide the proposed therapies into 'well-validated core therapies' and 'less well-validated therapies'. It is not clear how the authors assigned the therapies, since the criteria for this classification are not reported. By examining the summary,

A. Ceriello $(\triangle)$

Clinical Science Research Institute, Warwick Medical School, Clinical Science Building, University Hospital-Walsgrave Campus, University of Warwick,

Clifford Bridge Road,

Coventry CV2 2DX, UK

e-mail: antonio.ceriello@warwick.ac.uk where it is stated that the algorithm emphasises the 'achievement and maintenance of near normoglycaemia $\left(\mathrm{HbA}_{1 \mathrm{c}}<7.0 \%\right)$, it seems that the therapeutic suggestions, particularly, but not only, for insulin therapy, are not in line with this goal $[3,4]$. Almost all the studies comparing the two approaches have shown that targeting postprandial hyperglycaemia is superior to targeting fasting glycaemia in terms of reaching this goal, using insulin or other treatments [3, 4]. Is it possible that not one patient would benefit from receiving prandial insulin therapy instead of a long-acting insulin during an early phase of the disease? Particularly considering that, during the early stage of the disease, the loss of the first phase of insulin secretion, producing high levels of glycaemia after meals [3], is the key feature of the disease? Certainly, the authors can claim that this strategy is associated with a higher incidence of hypoglycaemia, but, looking at two main trials, INITIATE and $4 \mathrm{~T}[5,6]$, is it clinically relevant that, in order to reach a better $\mathrm{HbA}_{1 \mathrm{c}}$ level, some patients have to suffer an episode of hypoglycaemia every 1 to 2 months instead of every 4 months?

Finally, in the summary it is also stated that 'rapid addition of medication [...]', consistent with the evidence that 'lower levels of glycaemia at the time of initial therapy are associated with lower $\mathrm{HbA}_{1 \mathrm{c}}$ levels over time and decreased long-term complications'. This is also the rationale for immediately initiating metformin treatment, without waiting for the possible effect of lifestyle intervention. However, examination of this point with respect to adjustment of insulin therapy reveals, to our surprise, that clinicians would need to wait more than 6 months before adjusting the therapy. Which, therefore, is the best way of determining therapeutic options?! 
Duality of interest The author declares that there is no duality of interest associated with this manuscript.

\section{References}

1. Nathan DM, Buse JB, Davidson MB et al (2009) Medical management of hyperglycaemia in type 2 diabetes mellitus: a consensus algorithm for the initiation and adjustment of therapy. A consensus statement from the American Diabetes Association and the European Association for the Study of Diabetes. Diabetologia $52: 17-30$

2. Nathan DM, Buse JB, Davidson MB et al (2009) Medical management of hyperglycemia in type 2 diabetes mellitus: a consensus algorithm for the initiation and adjustment of therapy.
A consensus statement from the American Diabetes Association and the European Association for the Study of Diabetes. Diabetes Care 32:193-203

3. Ceriello A, Colagiuri S, Gerich J, Tuomilehto J, Guideline Development Group (2008) Guideline for management of postmeal glucose. Nutr Metab Cardiovasc Dis 18:S17-S33

4. Woerle HJ, Neumann C, Zschau S (2007) Impact of fasting and postprandial glycemia on overall glycemic control in type 2 diabetes. Importance of postprandial glycemia to achieve target $\mathrm{HbA}_{1 \mathrm{c}}$ levels. Diabetes Res Clin Pract 77:280-285

5. Raskin P, Allen E, Hollander P et al (2005) Initiating insulin therapy in type 2 diabetes: a comparison of biphasic and basal insulin analogs. Diabetes Care 28:260-265

6. Holman RR, Thorne KI, Farmer AJ (2007) Addition of biphasic, prandial, or basal insulin to oral therapy in type 2 diabetes. N Engl J Med 357:1716-1730 